\title{
Anatomía de la corteza de algunas Gimnospermas
}

\author{
Laura Yáñez Espinosa y Teresa Terrazas \\ Programa de Botánica, Colegio de Postgraduados. Montecillo, Estado de México, 56230 México. \\ E-mail winchi@colpos.colpos.mx
}

\begin{abstract}
Resumen. El estudio sobre la diversidad estructural de la corteza de 17 especies de gimnospermas se realizó con objeto de describir sus características macro y microscópicas, elaborar una clave de identificación y compararlas con la clasificación propuesta por den Outer (1967). La corteza externa permite identificar algunas especies en el campo. Se encontraron características anatómicas antes no reportadas para algunos taxa como por ejemplo, cristales tipo arenisca sobre las paredes de los diferentes tipos celulares en Araucariaceae y Taxodiaceae, ausencia de fibras en Cupressus guadalupensis y linificación de las células cribosas del floema colapsado en Pinus. Diez especies, por primera vez descritas, se pueden asignar claramente en alguno de los tres tipos propuestos por den Outer para el floema secundario de gimnospermas. Sin embargo, las ideas filogenéticas que argumenta den Outer para la especialización del floema secundario en gimnospermas han sido cuestionadas con base en los trabajos recientes sobre gimnospermas fósiles y los análisis cladísticos.

Palabras clave: corteza, floema secundario, células cribosas, gimnospermas, Araucariaceae, Cupressaceae, Ginkgoaceae, Pinaceae, Taxaceae, Taxodiaceae

Abstract. The study of bark structural diversity of 17 gymnosperms was performed to describe it macro and microscopically, to elaborate a key and to compare them with den Outer's classification (1967). External bark allows to identify several species in the field. New anatomical features not reported previously were found, e.g. crystals in cellular walls in Araucariaceae and Taxodiaceae, lack of fibers in Cupressus guadalupensis and lignified sieve cells in the collapsed phloem of Pinus species. Ten species, described for the first time, were assigned to one of the types proposed by den Outer. Although the phylogenetic ideas established for the secondary phloem specialization suggested by den Outer have been questioned by the recent studies on fossil gymnosperms and cladistic analysis.
\end{abstract}

Key words: bark, secondary phloem, sieve cells, gymnosperms, Araucariaceae, Cupressaceae, Ginkgoaceae, Pinaceae, Taxaceae, Taxodiaceae.

$\mathbf{L}$ as gimnospermas incluyen algunos de los árboles más importantes y útiles del mundo, que crecen especialmente en los bosques templados y fríos de los hemisferios norte y sur (Harlow et al., 1991). Muchas especies de gimnospermas son valiosas como árboles maderables, ornamentales, medicinales o alimenticios. También son fuente de aceites esenciales y otros productos. Particularmente, su corteza es importante ya que a partir de ella se obtienen tintes, taninos, resinas y algunos compuestos farmacéuticos, además es utilizada para la decoración de artesanías y la construcción de habitaciones (Jones, 1988).
La corteza es una estructura compleja en cuanto a su origen y organización, y se compone principalmente de dos zonas. La interna que incluye el floema secundario y la externa formada por la peridermis y el ritidoma (Esau, 1953; Prance y Prance, 1993). El floema secundario de las gimnospermas se parece al xilema secundario de este grupo en su relativa simplicidad estructural. El sistema axial presenta células cribosas, parénquima y frecuentemente esclerénquima; mientras el sistema horizontal se caracteriza por las células de parénquima radial y en ocasiones células albuminosas (Esau, 1953). A pesar de esta sim- 
plicidad estructural den Outer (1967) propuso tres patrones de arreglo. El tipo Pseudotsuga menziesii, donde el floema secundario presenta bandas anchas de células cribosas, que pueden o no tener una secuencia regular; el tipo Ginkgo biloba, donde las bandas de células cribosas se alternan con bandas de células parenquimatosas y el tipo Chamaecyparis pisifera donde las bandas de los diferentes tipos celulares tienen un patrón estratificado regular.

Aunque los estudios sobre la estructura anatómica de la corteza de gimnospermas pueden ser de gran utilidad, son escasos tanto en México como en el mundo. Abbe y Crafts (1939) estudiaron el floema de algunas coníferas, Chang (1954) la anatomía de la corteza en varias coníferas de Norteamérica, Srivastava (1963) trabajó con varias especies de la familia Pinaceae, Isenberg (1943) con Sequoia sempervirens, Eremin (1978) con las especies de pinos de la antigua Unión Soviética, Liphschitz et al. (1981) con Cupressus sempervirens y Nunes et al. (1996) con Pinus pinaster. Sin embargo, en México solamente existen algunas descripciones macroscópicas, como las hechas para las familias Pinaceae, Taxodiaceae y Cupressaceae por Martínez (1948, 1953), para el género Pinus por Perry (1990) y para Taxus globosa por Zamudio (1992). Con base en lo anterior, se llevó a cabo un estudio sobre la diversidad estructural de la corteza de algunas gimnospermas con los objetivos de describir su estructura macroscópica y microscópica, elaborar una clave de identificación con base en las características de la corteza, y comparar los caracteres anatómicos de las especies estudiadas con los tipos propuestos por den Outer (1967).

\section{Materiales y métodos}

Se seleccionó el campus de la Universidad Autónoma Chapingo para la recolecta de material porque existe una considerable diversidad de especies tanto nativas como introducidas de las familias Araucariaceae, Cupressaceae, Ginkgoaceae, Pinaceae y Taxodiaceae (Gutiérrez-Hernández, 1997). Los árboles se localizan en los diferentes jardines creciendo como ornamentales y se encuentran en buen estado ya que se les proporciona riego, podas y aclareos en algunos casos. La muestra de Taxus proviene de una colecta realizada en el estado de Hidalgo. Se recolectó una muestra de la corteza, incluyendo cámbium y en algunos casos xilema secundario, de 17 especies pertenecientes a 11 géneros y 6 familias de gimnospermas (cuadro 1).

Las muestras se recolectaron a $1.30 \mathrm{~m}$ del suelo con un sacabocado de $25 \mathrm{~mm}$ de diámetro, enseguida se fijaron en FAA (Johansen, 1940) durante 24 h y se almacenaron en GAA (glicerina-alcohol etílico 95\%agua, 1:1:1) para evitar su endurecimiento. Cortes transversales y radiales, así como tangenciales seriados de cámbium a peridermis se hicieron con un micrótomo de deslizamiento a $20-25 \mathrm{~mm}$ de grosor para la mayoría de las muestras y de 35 a $50 \mathrm{~mm}$ para Ginkgo biloba y las especies de Araucaria. La mitad de los cortes se aclararon con cloro comercial diluido al $50 \%$ en agua. Posteriormente todos los cortes se tiñeron con safranina-verde fijo (Johansen, 1940), se montaron con resina sintética y, en ellos se llevaron a cabo las observaciones de las características anatómicas para su descripción y comparación. Para la caracterización macroscópica de la corteza se siguieron las recomendaciones de Junnika (1994).

\section{Resultados}

A continuación se presenta la descripción de las características macroscópicas y anatómicas de la corteza de las 17 especies estudiadas. Algunas características macroscópicas se ilustran en las figuras 1 a 3 y las microscópicas en las figuras 4 a 18 . Por sus características anatómicas Pinus oaxacana, P. patula, P. cembroides, $P$. maximartinezii y Cedrus libani se agrupan en el tipo Pseudotsuga menziesii propuesto por den Outer (1967). Ginkgo biloba, Taxus globosa, Araucaria excelsa y A. bidwillii se clasifican en el tipo Ginkgo biloba, mientras que Cryptomeria japonica, Taxodium mucronatum, Juniperus monosperma, Cupressus lusitanica, C. arizonica, C. guadalupensis, Chamaecyparis lawsoniana y Calocedrus decurrens en el tipo Chamaecyparis pisifera también propuestos por den Outer (1967). Una clave dicotómica con las características morfológicas del ritidoma y las anatómicas para las especies se presenta como apéndice.

Floema secundario con bandas anchas de células cribosas, tipo Pseudotsuga menziesii

\section{Cedrus libani (figura 19)}

Características macroscópicas. Corteza externa fisurada color ocre, con fisuras poco profundas más oscuras.

Características microscópicas. Ritidoma de cinco peridermis. El felema más interno de ocho estratos de células de paredes gruesas colapsadas; felodermis de cuatro estratos de células de pared delgada. Entre las peridermis floema colapsado con parénquima expandido y suberificado, células cribosas colapsadas en manchones y esclereidas del parénquima axial y radial. Células cribosas abundantes, en contacto con las albuminosas y las de parénquima radial. Áreas cribosas distribuidas en forma continua en las paredes 


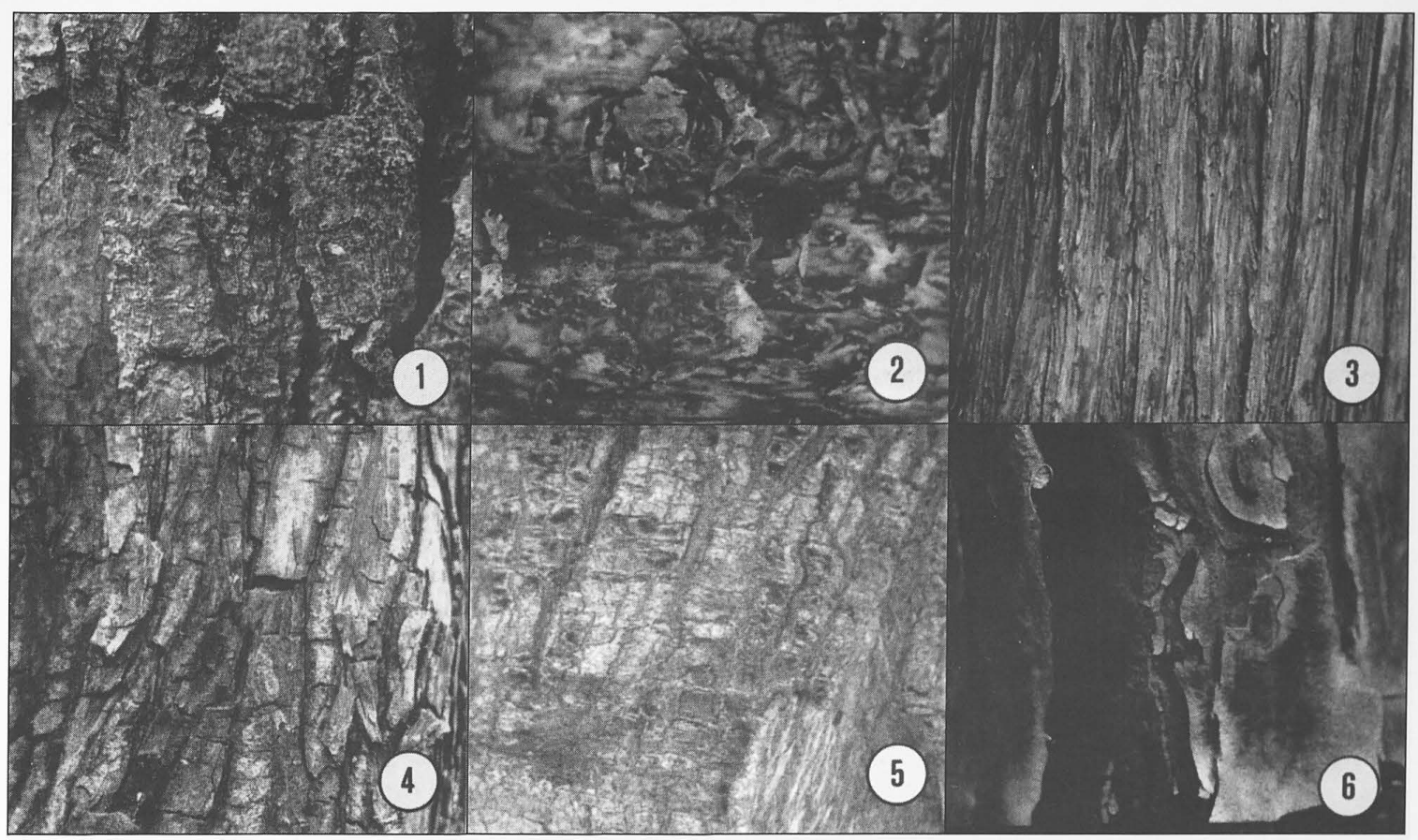

Figuras 1-6. Características macroscópicas de la corteza. 1. Pinus patula. Corteza fisurada 2. Araucaria excelsa. Corteza escamosa. 3. Cryptomeria japonica. Corteza laminar. 4. Taxodium mucronatum. Corteza fibrosa, escamas rectangulares. 5. Cupressus arizonica. Corteza fibrosa, escamas irregulares. 6. Calocedrus decurrens. Corteza fibrosa, láminas exfoliantes.

radiales, circulares a obladas, muy anchas con 6 a 15 grupos de poros y reticuladas. Células albuminosas escasas, ocasionalmente en un margen del radio. Células del parénquima axial en bandas; las células casi cuadradas con taninos, mientras las rectangulares con taninos y cristales rectangulares, generalmente cerca de los radios. Radios numerosos, homogéneos, uniseriados, 5 a 24 células de alto, células procumbentes con abundantes granos de almidón, ligeramente dilatados y algunos esclerificados cerca de la peridermis, al igual que el parénquima axial asociado.

Pinus (P. cembroides, P. maximartinezii, P. oaxacana y $P$. patula) (figuras 1, 7, 10, 13, 16)

Características macroscópicas. Corteza externa fisurada, fisuras poco profundas color pardo grisáceo en P. cembroides y P. oaxacana. Pinus oaxacana de escamas pequeñas, ligeramente rectangulares, pero grandes e irregularmente rectangulares en $P$. maximartinezii. Pinus patula de fisuras profundas, alargadas color pardo rojizo. Exudado resinoso en las cuatro especies.

Características microscópicas. Ritidoma presente, pero ausente en P. maximartinezii. Ritidoma con cin- co peridermis en $P$. patula y 12 en $P$. oaxacana. En $P$. oaxacana y $P$. patula el felema más interno de 5 a 6 estratos de células de paredes delgadas suberificadas; felodermis de 4 a 5 estratos de células de pared delgada y abundantes taninos, pero de paredes muy gruesas y lignificadas en el ritidoma. En $P$. cembroides y $P$. maximartinezii, felema con dos tipos celulares, las más alejadas del felógeno esclereidas de paredes gruesas y, las más cercanas a éste de 1 a 2 estratos de células de paredes delgadas expandidas en el ritidoma; felodermis de 4 a 5 estratos de células también esclerificadas en el ritidoma. Entre las peridermis el parénquima dilatado fuertemente y las células cribosas colapsadas con abundantes taninos le confieren una apariencia distintiva al ritidoma en $P$. oaxacana y $P$. patula. Células cribosas abundantes, en contacto con el parénquima radial exclusivamente por medio de las albuminosas. Áreas cribosas en una sola hilera en las paredes radiales, distribuidas en forma discontinua en $P$. oaxacana y $P$. patula, pero continua en $P$. cembroides y $P$. maximartinezii, circulares a obladas, solo circulares en $P$. oaxacana, con una retícula distintiva entre los grupos de poros, con 5 a 7 grupos de poros en $P$. cembroides. Células albuminosas exclusivamen- 
Cuadro 1. Familia, especie y origen del material recolectado para caracterizar macro y microscópicamente la corteza de algunas gimnospermas creciendo en el campus de la UACh y el estado de Hidalgo.

\begin{tabular}{lll}
\hline Familia & Especie & Origen \\
\hline Araucariaceae & Araucaria excelsa (Lamb.) R. Br. & Noreste de Australia \\
Araucariaceae & A. bidwillii Hook & Chile \\
Cupressaceae & Calocedrus decurrens (Torrey) Florin & México \\
Cupressaceae & Chamaecyparis lawsoniana (Murr.) Parl. & Norteamérica \\
Cupressaceae & Cupressus arizonica Greene & México \\
Cupressaceae & C. guadalupensis S. Wats. & México \\
Cupressaceae & C. lusitanica Mill. & México \\
Cupressaceae & Juniperus monosperma (Engelm.) Sarg. & Norteamérica \\
Ginkgoaceae & Ginkgo biloba L. & China, Japón \\
Pinaceae & Cedrus libani A. Rich. & Asia menor \\
Pinaceae & Pinus cembroides Zucc. & México \\
Pinaceae & P. maximartinezii Rzedowski & México \\
Pinaceae & P. oaxacana Mirov & México \\
Pinaceae & P. patula Schl. \& Cham. & México \\
Taxaceae & Taxus globosa Schlecht. & México \\
Taxodiaceae & Cryptomeria japonica D.Don & Japón, Centro de China \\
Taxodiaceae & Taxodium mucronatum Ten. & México \\
\hline
\end{tabular}

te en la región marginal uniseriada de los radios, irregulares casi erectas en $P$. oaxacana y $P$. patula y cuadradas en $P$. cembroides y $P$. maximartinezii. Células del parénquima axial dispersas entre células cribosas o formando bandas uniseriadas en $P$. cembroides y $P$. maximartinezii; las células circulares en corte transversal con taninos y de mayor tamaño al alejarse del cámbium; otras células rectangulares en corte transversal con taninos y cristales prismáticos en $P$. cembroides y $P$. maximartinezii, estiloides en $P$. patula, pero ausentes en $P$. oaxacana. Radios heterogéneos, uniseriados, a excepción de $P$. patula con radios uni y biseriados; altura de 2 a 9 células en $P$. oaxacana y de 10 a 19 en las otras especies estudiadas, células procumbentes con taninos, ligera dilatación en $P$. maximartinezii y $P$. patula. Canales resiníferos longitudinales y radiales en $P$. maximartinezii y únicamente radiales en $P$. cembroides, $P$. oaxacana y $P$. patula.

Floema secundario con bandas de células cribosas y bandas de células de parénquima, tipo Ginkgo biloba

\section{Araucaria (A. bidwillii y A. excelsa) (figuras 2, 8, 17, 20)}

Características macroscópicas. Corteza externa escamosa color pardo grisáceo en $A$. bidwillii y pardo amarillento en $A$. excelsa, con escamas papiráceas adherentes, de tamaño regular color pardo rojizo, exudado resinoso e hilo entrecruzado.

Características microscópicas. Ritidoma de 3 a 4 peridermis. El felema de la peridermis más interna de siete estratos de células suberificadas de pared delgada, ligeramente colapsadas; felodermis de 4 a 7 estratos de células, las más internas con abundantes taninos y cristales romboédricos sobre las paredes. Entre peridermis el tejido colapsado y suberificado. Células cribosas en proporción similar a las células del parénquima, angulosas en corte transversal con cristales romboédricos sobre las paredes en $A$. excelsa y $\sin$ cristales en $A$. bidwillii, en contacto con las albuminosas y las del parénquima radial y colapsadas muy cerca de cámbium. Áreas cribosas distribuidas en forma continua sobre la pared celular en $A$. bidwillii y en grupos discontinuos en $A$. excelsa, circulares con 4 a 6 grupos de poros en $A$. bidwillii y hasta diez en A. excelsa. Células albuminosas intercaladas en las bandas de parénquima. Células del parénquima axial en bandas tangenciales cortas de 2 y 3 células, pero de arreglo irregular al alejarse del cámbium por la esclerificación del parénquima radial; algunas células con granos de almidón en A. excelsa y abundantes cristales romboédricos sobre las paredes, en contacto con las albuminosas y otras del parénquima axial, pero no con las células cribosas. Fibras de paredes gruesas y lumen reducido en las bandas tangenciales de parénquima; cristales romboédricos pequeños sobre las paredes de las fibras en A. bidwillii. Radios homogéneos, uniseriados, 2 a 4 células de alto en $A$. bidwillii y 4 a 10 células en $A$. excelsa, células predominantemente cuadradas, numerosos cristales sobre las paredes de las células en $A$. excelsa y escasos en $A$. bidwillii; algunos dilatados ligeramente y otros poco 


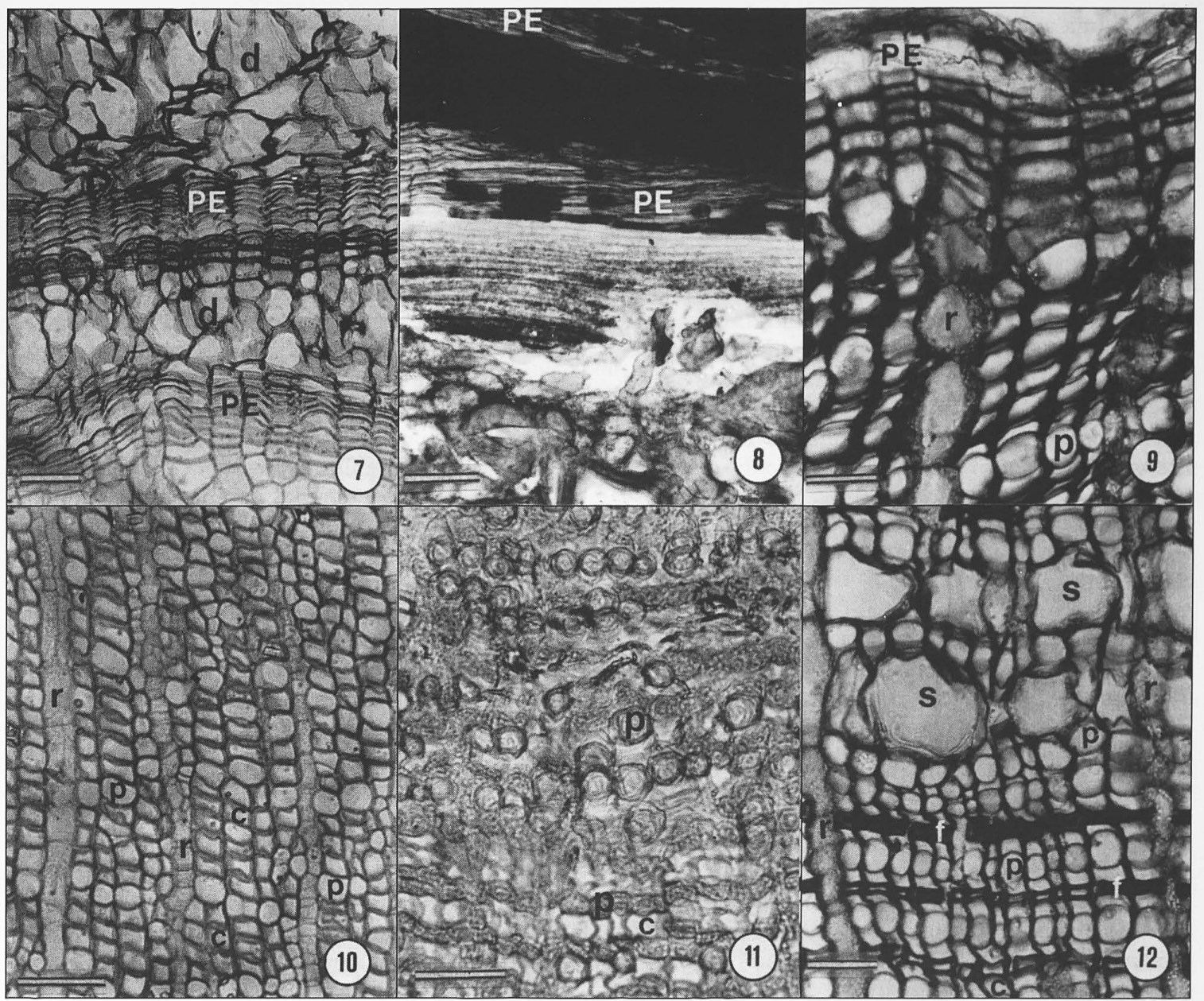

Figuras 7-12. Características microscópicas de la corteza representando de izquierda a derecha los tipos de arreglo Pseudotsuga menziesii, Ginkgo biloba y Chamaecyparis pisifera (den Outer, 1967). Cortes transversales. 7. Pinus patula. Peridermis sucesivas y ritidoma con células de parénquima fuertemente dilatadas. 8. Araucaria excelsa. Peridermis sucesivas con células colapsadas y suberificadas. 9. Cupressus guadalupensis. Peridermis ondulada. 10. Pinus patula. Arreglo de células cribosas en bandas anchas. 11. Ginkgo biloba. Arreglo en bandas de células cribosas y de parénquima. 12. Calocedrus decurrens. Arreglo de bandas estratificadas. $\mathrm{PE}=$ peridermis; $\mathrm{p}=$ parénquima; $\mathrm{d}=$ parénquima dilatado; $\mathrm{s}=$ esclereida; $\mathrm{r}=$ radio; $\mathrm{c}=$ célula cribosa. Escala 7, 8, 9,10,11 = $100 \mu \mathrm{m} ; 12=50 \mu \mathrm{m}$.

esclerificados al colapsarse las células cribosas, pero fuertemente esclerificados cerca de peridermis. Canales resiníferos longitudinales pequeños, circulares con 8 a 10 células epiteliales, cerca de la peridermis ligeramente obliterados como consecuencia del proceso de esclerificación radial.

Ginkgo biloba (figuras 11, 14)

Características macroscópicas. Corteza externa rugosa, ligeramente reticulada color pardo grisáceo.
Características microscópicas. Sin ritidoma. Peridermis de 8 a 12 estratos de células de felema de paredes suberificadas no colapsadas; felodermis de 2 a 3 estratos de células de paredes delgadas con cloroplastos. Células cribosas en proporción similar a las del parénquima axial, rectangulares en corte transversal. Áreas cribosas distribuidas en forma discontinua a lo largo de la pared celular, grandes, irregulares a circulares con 3 o 4 grupos de poros, en contacto con las albuminosas y las del parénquima radial. Células albuminosas en las bandas de parénquima. Células del 
parénquima axial en bandas tangenciales regulares, pero irregulares al alejarse del cámbium, en contacto con las albuminosas y otras del parénquima, pero no con las células cribosas; la mayoría con abundantes granos de almidón, otras idioblastos con taninos de color rojo. Drusas muy abundantes en el floema colapsado. Fibras de paredes gruesas y lumen reducido con taninos, intercaladas irregularmente en las bandas tangenciales de parénquima con taninos cerca de la peridermis. Radios homogéneos, uniseriados, 2 y 3 células de alto, células procumbentes cortas, ligeramente dilatados en el floema colapsado. Canales resiníferos longitudinales de gran tamaño, sin trayectoria recta.

\section{Taxus globosa}

Características macroscópicas. Corteza externa escamosa, escamas cuadrangulares pequeñas color pardo claro.

Características microscópicas. Sin ritidoma. El felema de 3 a 5 estratos de células no colapsadas suberificadas con abundantes taninos; felodermis de 2 a 3 estratos de células, con el más interno lignificado. Restos de peridermis previas y floema colapsado adheridos a algunas células del falema. Células cribosas en bandas tangenciales uniseriadas con cristales tipo arenisca sobre sus paredes. Áreas cribosas distribuidas en forma continua sobre la pared celular, circulares a obladas con 3 a 5 grupos de poros, en contacto con las albuminosas y las del parénquima radial. Células albuminosas en las bandas de parénquima, en contacto con las del parénquima y las células cribosas; tanto las células cribosas como las albuminosas se colapsan al mismo tiempo. Células del parénquima axial en bandas tangenciales uniseriadas alternadas con 2 a 4 bandas de células cribosas, abundantes taninos y cristales tipo arenisca sobre las paredes; ligera dilatación en el floema colapsado por el incremento celular. Fibras escasas, dispersas entre las bandas tangenciales de parénquima, paredes delgadas, punteaduras restringidas a las paredes radiales y abundantes cristales tipo arenisca sobre éstas. Radios homogéneos, uniseriados, 3 a 23 células de alto, células procumbentes cortas, sin dilatación.

Floema secundario con tipos celulares estratificados, tipo Chamaecyparis pisifera

\section{Calocedrus decurrens (figuras 6, 12)}

Características macroscópicas. Corteza externa fibrosa, láminas cuadrangulares, de tamaño regular, exfoliantes color pardo muy oscuro y exudado resinoso.
Características microscópicas. Ritidoma de dos peridermis. El felema más interno de 4 a 5 estratos de células suberificadas y colapsadas; felodermis de cuatro estratos de células, paredes delgadas sin contenidos. Entre peridermis floema secundario irregularmente estratificado debido a la expansión de las células del parénquima axial y radial. Células cribosas en bandas tangenciales uniseriadas, rectangulares con escasos cristales romboédricos sobre sus paredes radiales. Áreas cribosas distribuidas en forma espaciada, circulares a ovales con 5 a 6 grupos de poros, en contacto con otras células cribosas y las del parénquima. Células albuminosas dispersas en las bandas de parénquima. Células del parénquima axial en bandas tangenciales uniseriadas, alternándose con bandas de células cribosas y de fibras, abundantes taninos y cristales romboédricos sobre las paredes radiales; dilatación de las paredes anticlinales de algunas células de la banda cerca de cámbium; pero mayor número de células expandidas y lignificadas en el floema colapsado, modificando el arreglo estratificado. Fibras en bandas tangenciales uniseriadas cada seis series, rectangulares en corte transversal, punteaduras simples en las paredes radiales; pero cuadrangulares con paredes gruesas y lumen reducido en el floema colapsado; ocasionalmente algunas fibras dilatadas fuertemente. Radios homogéneos, uniseriados con escasos parcialmente biseriados, 1 a 10 células de alto, células procumbentes con abundantes cristales romboédricos sobre las paredes y sin dilatación. Canales resiníferos longitudinales numerosos, ovales a elípticos en sección transversal, incrementando su tamaño al acercarse a la peridermis, conspicuos a simple vista, células epiteliales colapsadas y suberificadas en el ritidoma.

\section{Chamaecyparis lawsoniana (figuras 15, 21)}

Características macroscópicas. Corteza externa fibrosa, láminas adherentes color pardo grisáceo.

Características microscópicas. Ritidoma de tres peridermis. El felema más interno de 4 a 5 estratos de células suberificadas, algunas colapsadas y abundantes taninos; felodermis de cuatro estratos de células de paredes delgadas. Entre las peridermis floema colapsado con las células de parénquima expandidas y lignificadas y las fibras sin arreglo. Células cribosas en bandas tangenciales uniseriadas alternado con bandas de parénquima, de células cribosas y de fibras, con numerosos cristales romboédricos sobre las paredes, pero ausentes sobre las áreas cribosas. Áreas cribosas distribuidas en forma continua, circulares a obladas con grupos de poros numerosos y pequeños. Células albuminosas dispersas en las bandas del pa- 
rénquima. Células del parénquima axial en bandas tangenciales uniseriadas, tamaño similar a las células cribosas, paredes delgadas, con taninos y cristales romboédricos sobre las paredes; cada 6 u 8 series expansión de las células de la banda parenquimatosa cuando las células cribosas adyacentes se colapsan, pero cuadrangulares con paredes gruesas y lumen reducido en el floema colapsado. Fibras en bandas tangenciales uniseriadas, de forma rectangular en corte transversal, punteaduras simples en las paredes radiales, cerca de cámbium con paredes delgadas y lumen amplio, pero algunas dilatadas fuertemente en el floema colapsado. Radios homogéneos, uniseriados, 5 a 18 células de alto, células procumbentes con cristales romboédricos sobre sus paredes y dilatación ligera cerca de la peridermis.

\section{Cryptomeria japonica (figura 3)}

Características macroscópicas. Corteza externa laminar, láminas rectangulares, exfoliantes color pardo rojizo y entre láminas amarillento.

Características microscópicas. Ritidoma de dos peridermis. El felema más interno de varios estratos de células colapsadas radialmente con abundantes taninos; felodermis de dos estratos de células sin contenidos y espacios intercelulares distribuidos en forma regular entre las células, manteniéndose en el ritidoma. Entre peridermis el floema colapsado estratificado con abundantes taninos. Células cribosas en bandas tangenciales uniseriadas, rectangulares, abundantes cristales romboédricos sobre las paredes radiales. Áreas cribosas distribuidas en forma continua sobre

Cuadro 2. Principales características macroscópicas y microscópicas de la corteza de algunas gimnospermas.

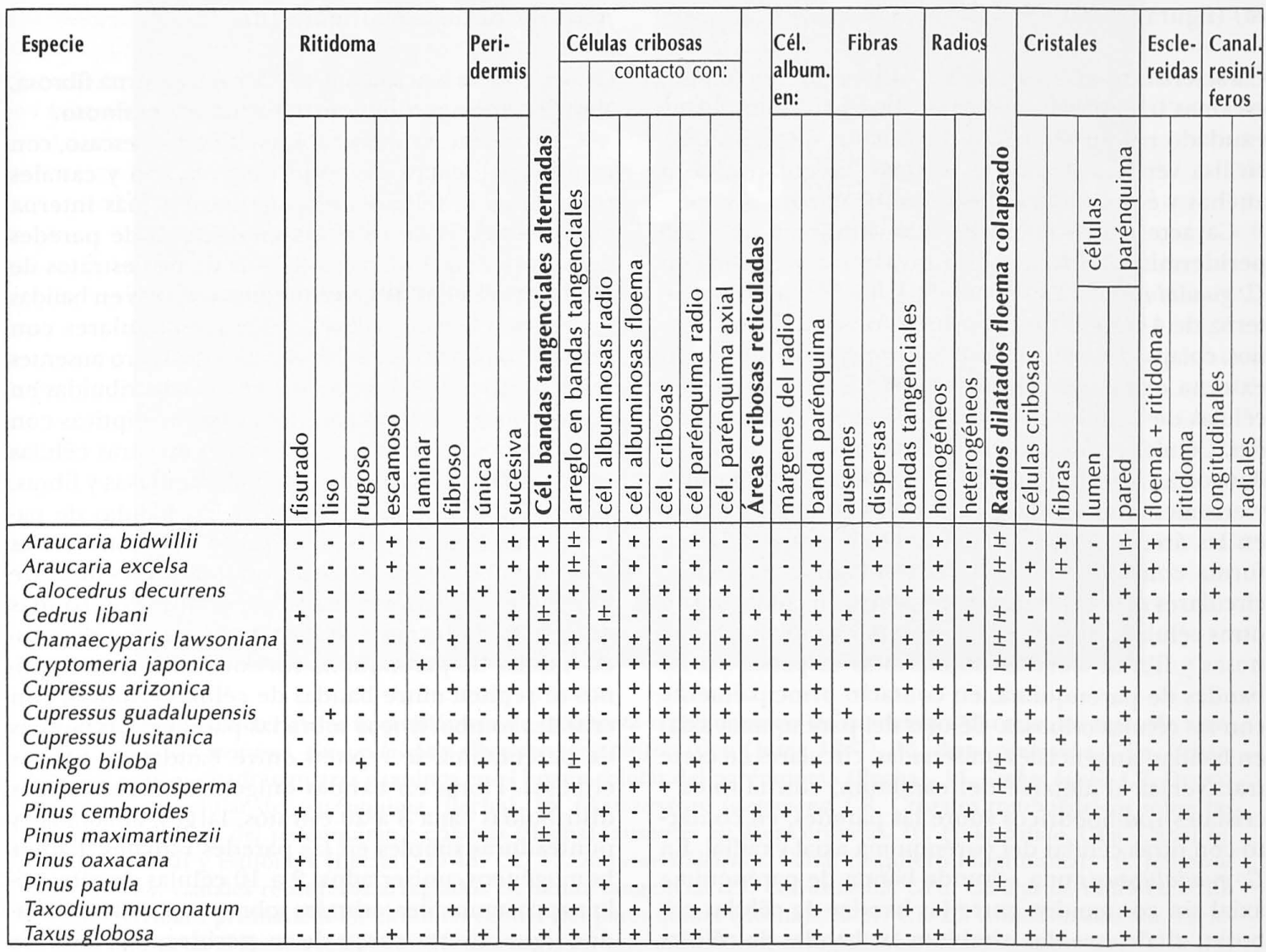

Síbolos: + presente; - ausente; \pm parcialmente. 
las paredes, circulares a ovales, anchas con 2 a 5 grupos de poros, en contacto con otras células cribosas y las del parénquima. Células albuminosas distribuidas entre las del parénquima axial, conectándolas con las células cribosas. Células de parénquima axial también en bandas tangenciales uniseriadas, alternándose con bandas de células cribosas y otras de parénquima con abundantes taninos, en contacto con las células albuminosas y otras de parénquima axial, pero no con las células cribosas y cristales romboédricos sobre las paredes. Fibras en bandas tangenciales uniseriadas, casi continuas cerca de la peridermis, alternándose con las bandas de parénquima y las de células cribosas, casi cuadradas en corte transversal, paredes más gruesas al alejarse de cámbium y punteaduras simples en las paredes radiales. Radios homogéneos, uniseriados, 2 a 13 células de alto, células procumbentes, abundantes taninos; por dilatación moderada en el floema colapsado radios biseriados.

Cupressus (C. arizonica, C. guadalupensis y C. lusitanica) (figuras 5, 9)

Características macroscópicas. Corteza externa fibrosa, escamas irregulares, angostas color pardo grisáceo y exudado resinoso en C. lusitanica. En C. guadalupensis lisa verdosa, también escamas irregulares, pero anchas y exfoliantes color castaño rojizo.

Características microscópicas. Ritidoma de 2 a 3 peridermis; peridermis distintivamente ondulada en C. guadalupensis. El felema de la peridermis más interna de 4 a 5 estratos de células con abundantes taninos, colapsadas radialmente, excepto por la célula más externa expandida; felodermis de 2 a 3 estratos de células de paredes delgadas y cristales sobre las paredes. Células cribosas en bandas tangenciales uniseriadas cortas, interrumpidas por los radios, rectangulares y cristales romboédricos sobre sus paredes, excepto en las áreas cribosas. Áreas cribosas distribuidas en forma continua en las paredes radiales, pequeñas, circulares con 4 o 5 grupos de poros, en contacto con otras células cribosas, del parénquima radial, albuminosas y fibras. Células albuminosas dispersas en las bandas de parénquima, en contacto principalmente con las células cribosas. Células del parénquima axial en bandas tangenciales uniseriadas, circulares en corte transversal al alejarse del cámbium, con taninos y cristales romboédricos sobre las paredes, en contacto con otras células del parénquima axial y radial. En C. guadalupensis una segunda banda de parénquima axial sin contenidos entre las bandas de células cribosas; al alejarse del cámbium las bandas de células cribosas y algunas del parénquima colapsadas. Otras bandas de parénquima no se colapsan, pero contie- nen taninos en el floema colapsado. De tal manera que se repite el arreglo de bandas de parénquima con taninos, parénquima sin taninos, células cribosas, parénquima con taninos, parénquima sin taninos, células cribosas. Fibras en bandas uniseriadas en $C$. arizonica y C. lusitanica, pero ausentes en C. guadalupensis, punteaduras en las paredes radiales y tangenciales y cristales romboédricos sobre sus paredes; las bandas de fibras alternando regularmente con bandas de células cribosas, de parénquima con taninos, de células cribosas y de fibras hasta cerca de la peridermis, pero irregulares por dilatación de algunos radios. Radios homogéneos, uniseriados, de 2 a 12 células de alto en C. guadalupensis y C. lusitanica y hasta 23 en C. arizonica, células procumbentes, cristales sobre las paredes y en contacto con todos los tipos de células del floema, sin dilatación en C. guadalupensis y C. lusitanica, pero en C. arizonica dilatación en el parénquima radial y axial. Abundantes bolsas de resina en C. lusitana.

\section{Juniperus monosperma (figura 18)}

Características macroscópicas. Corteza externa fibrosa, láminas color pardo oscuro y exudado resinoso.

Características microscópicas. Ritidoma escaso, con restos de floema colapsado estratificado y canales resiníferos. El felema de la peridermis más interna de tres estratos de células suberificadas de paredes delgadas y colapsadas; felodermis de tres estratos de células de paredes delgadas. Células cribosas en bandas tangenciales uniseriadas cortas, rectangulares con cristales romboédricos sobre sus paredes, pero ausentes sobre las áreas cribosas. Áreas cribosas distribuidas en forma continua en las paredes radiales, elípticas con 4 a 6 grupos de poros, en contacto con otras células cribosas, del parénquima radial, albuminosas y fibras. Células albuminosas dispersas en las bandas de parénquima. Células del parénquima axial en bandas tangenciales uniseriadas; una banda de células de forma circular con taninos alternándose con bandas de células de forma rectangular sin contenidos. Estas bandas de parénquima sin contenido y con taninos se repiten entre bandas de células cribosas, con cristales romboédricos sobre las paredes. Las bandas de parénquima se repiten entre bandas de células cribosas. Fibras en bandas tangenciales uniseriadas distribuidas cada 8 a 20 estratos, largas, aplanadas y punteaduras simples en las paredes radiales. Radios homogéneos, uniseriados, 2 a 10 células de alto, células procumbentes, cristales sobre sus paredes, dilatados ligeramente cerca de la peridermis. Canales resiníferos longitudinales en bandas tangenciales, conspicuos a simple vista cerca de la peridermis. 


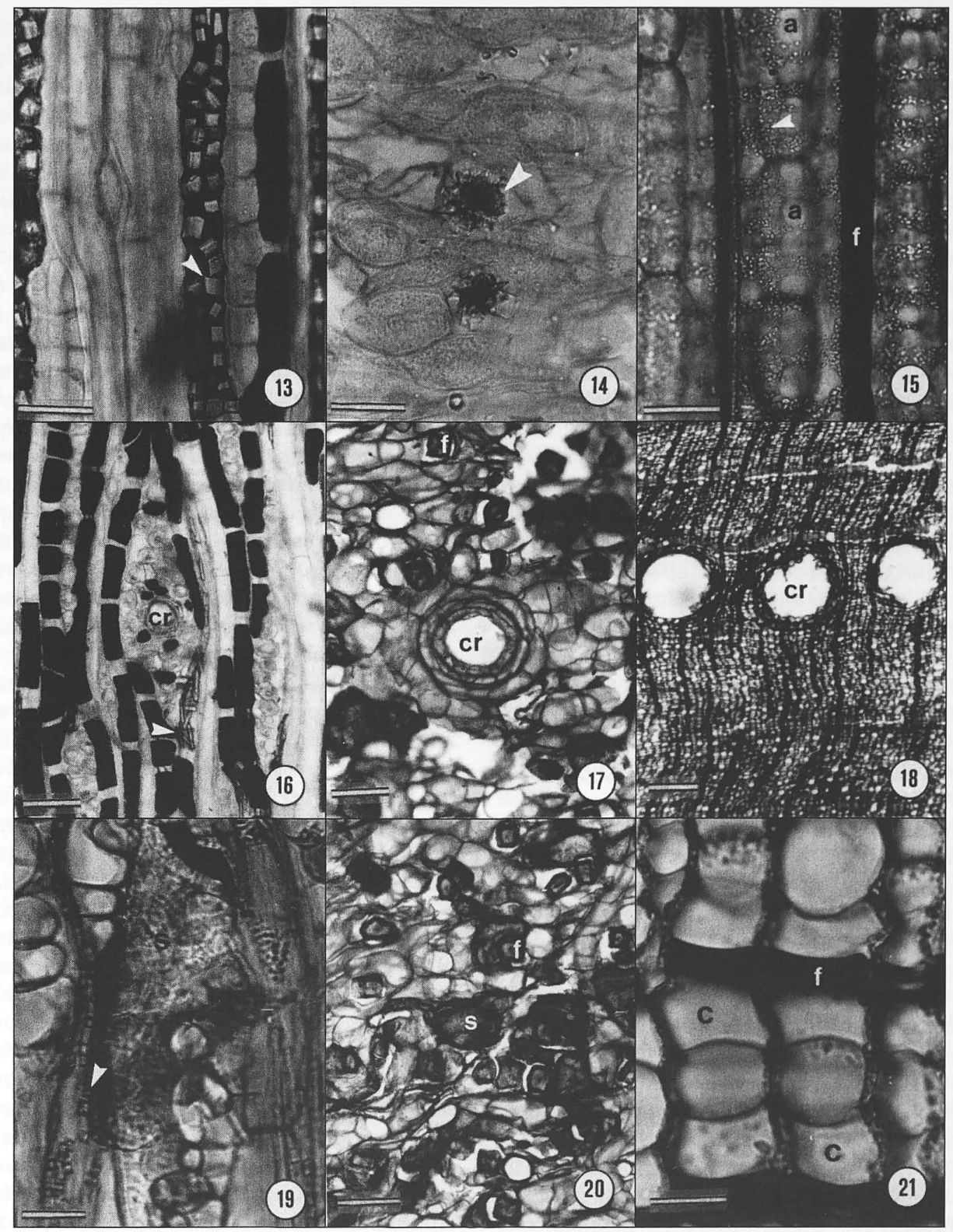

Figuras 13-21. Características microscópicas de la corteza representando de izquierda a derecha los tipos de arreglo Pseudotsuga menziesii, Ginkgo biloba y Chamaecyparis pisifera (den Outer, 1967). 13. Pinus cembroides. CTn. Cristales prismáticos cuadrangulares y taninos en el lumen celular del parénquima (flecha). 14. Ginkgo biloba. CT. Drusas en el lumen celular del parénquima (flecha). 15. Chamaecyparis lawsoniana. CR. Cristales romboédricos sobre las paredes celulares del parénquima y cribosas (flecha), ausentes en áreas cribosas. 16. Pinus patula. CTn. Canal resinífero radial y estiloides (flecha). 17-18. CT. 17. Araucaria bidwillii. Canal resinífero longitudinal. 18. Juniperus monosperma. Canales resiníferos arreglados en banda tangencial. 19. Cedrus libani. CTn. Células de radio esclerificadas y cristales prismáticos en el lumen celular del parénquima (flecha). 20-21. CT. 20. Araucaria bidwillii. Esclereidas y fibras en el floema colapsado. 21. Chamaecyparis lawsoniana. Fibras arregladas en bandas tangenciales. CT=corte transversal; $\mathrm{CR}=$ corte radial; $\mathrm{CTn}=$ corte tangencial; $\mathrm{f}=$ fibras; $\mathrm{s}=\mathrm{esclereida;} \mathrm{c}=$ célula cribosa; $\mathrm{a}=\mathrm{a}$ rea $\mathrm{cribosa}$; $\mathrm{cr}=\mathrm{canal}$ resinífero. Escala $18,21=20 \mu \mathrm{m} ; 15=30 \mu \mathrm{m} ; 13,14,19=50 \mu \mathrm{m} ; 16,17,20=100 \mu \mathrm{m}$. 


\section{Taxodium mucronatum (figura 4)}

Características macroscópicas. Corteza externa fibrosa, escamas rectangulares color castaño.

Características microscópicas. Ritidoma de 4 a 5 peridermis. El felema de la peridermis más interna de 2 a 3 estratos de células suberificadas, con taninos y colapsadas radialmente; felodermis de 2 a 4 estratos de células más o menos cuadradas sin contenidos. Entre peridermis regiones del floema secundario colapsado conservando su arreglo estratificado, bandas de fibras-parénquima-fibras, con abundantes taninos. Células cribosas arregladas en bandas tangenciales uniseriadas, rectangulares y con cristales romboédricos sobre las paredes. Áreas cribosas distribuidas en forma continua sobre las paredes laterales, irregulares a orbiculares, muy anchas con 5-6 grupos de poros. Células albuminosas dispersas en las bandas de parénquima, conectando a las células del parénquima y las células cribosas. Células del parénquima axial en bandas tangenciales uniseriadas, circulares en corte transversal al alejarse del cámbium, con taninos y cristales romboédricos sobre las paredes. Fibras en bandas tangenciales uniseriadas alternándose con bandas de parénquima axial y de células cribosas, rectangulares con paredes celulares más gruesas al alejarse del cámbium y punteaduras en las paredes radiales. Radios abundantes, homogéneos, uniseriados y biseriados, 2 a 41 células de alto, células procumbentes, cristales romboédricos sobre las paredes y sin dilatación.

Con el propósito de comparar y sintetizar los caracteres anatómicos de las especies se presenta el cuadro 2. Un ritidoma fisurado, contacto de las células cribosas exclusivamente con las albuminosas distribuidas en los márgenes de los radios, fibras ausentes, radios heterogéneos y canales resiníferos radiales son características exclusivas de las cinco especies de la familia Pinaceae estudiadas. Los miembros de Cupressaceae tienden a tener un ritidoma fibroso, excepto por C. guadalupensis. El arreglo de las fibras en banda lo comparten cinco de las especies de Cupressaceae estudiadas con las dos especies de Taxodiaceae (cuadro 2). Por otra parte, C. guadalupensis también se distingue de los otros miembros de Cupressaceae por la ausencia de fibras y esclereidas. Notoriamente el contacto de las células cribosas con otras células en Taxodiaceae y Cupressaceae se da con cuatro tipos celulares (cuadro 2). Hay una tendencia a que el esclerénquima esté disperso en Ginkgo biloba, Araucaria bidriillii, A. excelsa y Taxus globosa, tenga una distribución homogénea en Cupressaceae y Taxodiaceae y se restrinja al ritidoma y floema colapsado en Pinaceae (cuadro 2). Cristales pequeños sobre las paredes de células cribosas, parénquima axial y radial y ocasionalmente fibras se observaron en especies de Araucariaceae, Cupressaceae, Taxaceae y Taxodiaceae; mientras que en Pinaceae y Ginkgo biloba los cristales predominan en el lumen celular del parénquima (cuadro 2). En diez de las 17 especies estudiadas se observó dilatación de los radios en el floema colapsado.

\section{Discusión}

La composición del floema secundario y el arreglo celular en las gimnospermas tiene significado taxonómico y evolutivo (Chang, 1954; den Outer, 1967; Smoot, 1984b). Hay características macroscópicas como la apariencia de la corteza externa que permiten la identificación rápida de algunas especies en el campo, por lo que la clave que aquí se presenta puede ayudar a la identificación de algunas especies creciendo en el campus de la UACh y otros jardines del área metropolitana. Sin embargo, es conveniente realizar más observaciones que permitan comparar y confirmar el valor diagnóstico de las características macroscópicas.

Chang (1954) señaló que las características anatómicas de la corteza de gimnospermas son constantes a nivel genérico y la distinción entre familias es clara. Esta aseveración es apoyada en parte por resultados del presente trabajo, sin embargo la escasez de estudios anatómicos en este tejido no permite definir los límites genéricos o familiares. La familia Pinaceae tiene floema secundario que consiste exclusivamente de células cribosas y parénquima axial y radial. En algunos casos, las células cribosas y las del parénquima axial se distribuyen en bandas tangenciales pobremente organizadas, como se encontró en Pinus cembroides, P. maximartinezii y Cedrus libani. De acuerdo con den Outer (1967) y Srivastava (1963) el género Pinus no contiene esclerénquima en el floema secundario, sin embargo sí se observó lignificación en las células cribosas obliteradas del floema colapsado de las especies estudiadas, pero Chang (1954) sólo reporta la lignificación de dichas células en el ritidoma de P. monticola Dougl. En Cedrus libani además de las esclereidas derivadas del parénquima axial también reportadas por den Outer (1967) se observaron otras derivadas del parénquima radial. En otros géneros de Pinaceae, como en Abies y Pseudotsuga también se ha observado la presencia de esclerénquima (Chang, 1954; Grillos y Smith, 1959; den Outer, 1967). Asimismo, Chang (1954) separó la corteza de los pinos de los subgéneros Haploxylon y Diploxylon basado en la existencia de diferencias estructurales en el ritidoma y el floema secundario. En el ritidoma de Haploxylon las escamas son tangencialmente cortas, la perider- 
mis con frecuencia curvada en corte transversal, las células del parénquima poco expandidas y, en el floema no colapsado, la forma de los cristales prismáticos del parénquima es rectangular y los canales resiníferos comparativamente más abundantes que en el otro subgénero. Por otra parte, el ritidoma de $D i$ ploxylon difiere por presentar escamas más largas tangencialmente, peridermis recta o paralela al cámbium vascular, células del parénquima expandidas notablemente en el ritidoma y estiloides en el floema no colapsado. No todas las características anatómicas que distinguen a los subgéneros fueron observadas en las especies estudiadas, por ejemplo no se encontraron cristales de ningún tipo en el parénquima de $P$. oaxacana (Diploxylon). Mientras que en P. maximartinezii (Haploxylon) se observaron escasos canales resiníferos longitudinales, así como una sola peridermis debido a que el individuo muestreado aún es juvenil. Estas y otras características como presencia y abundancia de canales resiníferos y disposición de la peridermis más interna deberán de estudiarse en un mayor número de especies con objeto de evaluar el valor taxonómico de los caracteres anatómicos de la corteza propuestos por Chang (1954) para diferenciar a los subgéneros de Pinus.

Las gimnospermas, incluyendo la mayoría de las coníferas, las cícadas y Ginkgo tienen fibras en su floema secundario. Esta es una diferencia notable con el xilema secundario de gimnospermas donde las fibras están siempre ausentes (Panshin y De Zeeuw, 1980). La estructura de Ginkgo biloba coincide con la reportada por den Outer (1967). Srivastava (1964) señala que Cupressaceae, Podocarpaceae y Taxaceae se distinguen por presentar cristales pequeños sobre las paredes de los diferentes tipos celulares del floema. La presencia de estos cristales se corroboró en $\mathrm{Cu}$ pressaceae y Taxaceae, pero también se encontraron en Araucariaceae y Taxodiaceae. Sin embargo, por su tamaño los cristales sobre las paredes en Taxaceae se consideran tipo areniscas. Taxodiaceae y Cupressaceae tienen en común la estructura estratificada de bandas de células cribosas, fibras y parénquima y los cristales depositados sobre las paredes celulares. La estructura de Taxodium mucronatum es muy similar a la de T. distichum (Chang, 1954; den Outer, 1967); sin embargo, Chang no observó dilatación en el parénquima y las fibras tuvieron un diámetro similar en toda la corteza de T. distichum A.Rich. Cupressaceae se distinguen por la presencia de canales resiníferos longitudinales alineados tangencialmente. Las tres especies de Cupressus estudiadas difieren de C. macrocarpa Hartw. descrita por Chang (1954), por la presencia de radios exclusivamente uniseriados y la ausencia de canales resiníferos, de dilatación del pa- rénquima axial y radial en C. guadalupensis y C. lusitanica y de fibras en C. guadalupensis. La presencia de abundantes bolsas de resina en C. lusitana probablemente es una respuesta a daño mecánico (Hillis, 1987), lo cual podría comprobarse a través de un experimento de regeneración. Un mayor número de especies de Cupressus se está estudiando con objeto de evaluar diferencias anatómicas en la corteza que permitan distinguir especies o grupos de especies.

Las observaciones realizadas en Chamaecyparis lawsoniana y Juniperus monosperma coinciden con las descripciones para otras especies de estos géneros (Chang, 1954; den Outer, 1967); sin embargo C. pisifera Endl. difiere de C. lawsoniana en la ausencia de dilatación. Mientras que Calocedrus decurrens se distingue de los otras especies de Cupressaceae aquí estudiadas y las reportadas por otros autores (Chang, 1954; den Outer, 1967) por la temprana dilatación y lignificación de algunas células del parénquima axial a manera de idioblastos que le confieren una apariencia distintiva. Taxaceae y Araucariaceae se caracterizan por presentar fibras dispersas en el floema secundario. Además, Araucariaceae presenta esclereidas y canales resiníferos longitudinales dispersos en el floema no colapsado. Aunque la información acerca de Araucaria es muy escasa (Srivastava, 1964), se observaron características que separan bien a las dos especies estudiadas. Básicamente, A. excelsa presenta abundantes cristales sobre las paredes de las células cribosas y del parénquima, pero escasos en las fibras, a diferencia de $A$. bidwillii, que tiene abundantes cristales sobre las paredes de las fibras, escasos en las células de parénquima y ausentes en las células cribosas.

Es necesario resaltar que los trabajos sobre anatomía de la corteza de gimnospermas realizados a la fecha representan solamente el $23 \%$ del total de las especies, considerando que las gimnospermas vivientes comprenden cerca de 594 especies excluyendo al orden Cycadales (Krüssmann, 1985). Los resultados de este trabajo sugieren estudiar un mayor número de especies dada la diversidad encontrada a nivel específico.

Las diez especies descritas por primera vez se pueden clasificar en alguno de los tres tipos de arreglo celular propuestos por den Outer (1967) para el floema secundario de las gimnospermas. Las especies presentan las características distintivas de cada tipo, aunque el arreglo típico puede presentar variaciones posiblemente relacionadas con la edad del individuo muestreado (Srivastava, 1964); o bien, con la dilatación radial presente en algunas de las especies estudiadas. Esta última característica es considerada por otros autores como ausente en coníferas (Chang 1954; Srivastava 1963, 1964), pero nuestras observaciones no lo apoyan. 
Fisiológicamente las células albuminosas interactúan con otros tejidos que se comportan como fuente o como demanda, para acumular o liberar solutos en estos sitios y transportar materiales rápidamente por el sistema axial o radial. De acuerdo con den Outer (1967) el tipo Pseudotsuga menziesii es poco eficiente ya que los puntos de comunicación de las células albuminosas se restringen a las células marginales de los radios. No así en los dos tipos restantes, donde las zonas de comunicación se hacen más extensas al encontrarse las células albuminosas dispersas en las bandas de parénquima axial.

Den Outer definió las tendencias evolutivas del floema secundario de las gimnospermas como un incremento en la proporción de parénquima axial, reducción en el número de células albuminosas en los radios, asociada con su aumento en el sistema axial, incremento en las fibras y arreglo estratificado en bandas tangenciales de los diferentes tipos celulares. La dirección en estas tendencias se basa en la hipótesis sobre reducción evolutiva de las coníferas sugerida por los primeros investigadores en este grupo de plantas (Smoot, 1984b), lo cual no tiene congruencia con las hipótesis filogenéticas propuestas por Miller (1988). El arreglo celular del floema secundario de las gimnospermas se estableció aparentemente temprano en la evolución del grupo. La similitud del tejido floemático secundario en plantas vivientes de gimnospermas con el de los fósiles del Paleozoico (Smoot, 1984b y Taylor, 1991), apoya la teoría de que el tejido floemático es evolutivamente conservativo.

Fl arreglo del floema secundario que consiste únicamente de bandas anchas de células cribosas y de parénquima (tipos Pseudotsuga menziesii y Ginkgo biloba, den Outer, 1967) se presenta en los helechos con semillas, exceptuando a los medulosos, que incluyen bandas de fibras en su arreglo, y que constituyen uno de los cambios que distingue a este grupo (Miller, 1988; Rothwell y Serbet, 1994; Smoot, 1984a 1984b; Taylor, 1991). Smoot (1984a), menciona que los helechos con semillas del Carbonífero no tienen paralelo con las plantas vivientes; sin embargo, el arreglo de su floema secundario es similar al que se observa en algunos miembros de la familia Pinaceae (Pinus y Pseudotsuga) y las Gnetales. Este arreglo de bandas de células cribosas y parénquima también se encuentra en Ginkgoales y en las coníferas vivientes, Araucariaceae y Taxaceae, lo cual indica que es un carácter homoplásico en las gimnospermas. El análisis filogenético presentado por Miller (1988) sugiere que Pinaceae y Araucariaceae son grupos hermanos, sin embargo las diferencias en el arreglo del floema secundario no apoyan este clado. Miller (1988) también sugiere que Cupressaceae-Taxodiaceae están cercanamente relacionadas y deben incluirse en una sola familia, sugerencia que podría ser apoyada por las características que comparten de su corteza. De acuerdo con Iqbal y Zahur (1995), con base en los datos obtenidos en las últimas dos décadas, algunas tendencias definitivas de la filogenia del floema en grupos como los helechos o gimnospermas fósiles comienzan a surgir, pero las tendencias en los taxa vivientes aún no son conclusivas.

\section{Conclusiones}

La composición del floema secundario y el arreglo celular en las gimnospermas tienen significado taxonómico y evolutivo. Para el caso de las especies del género Pinus parece que los caracteres anatómicos que Chang (1963) determinó como distintivos de cada subgénero también contribuyen para distinguirlos, pero deberán de estudiarse en un mayor número de especies con objeto de evaluar su valor taxonómico. Las especies mexicanas de Cupressus presentan características que no se han reportado por otros autores, por lo cual más especies se encuentran bajo estudio actualmente para evaluar el posible valor diagnóstico de los caracteres anatómicos de la corteza.

La clasificación realizada por den Outer en 1967 separa los tres grandes tipos de floema secundario de acuerdo con su estructura y arreglo, en las que se pueden incluir las gimnospermas vivientes y fósiles. Sin embargo, la base filogenética que argumenta den Outer ha sido cuestionada con base en los trabajos recientes sobre gimnospermas fósiles y los análisis cladísticos.

\section{Agradecimientos}

Agradecemos a la Universidad Autónoma Chapingo por facilitar la recolecta del material; al M.Sc. Juan Ignacio Valdez Hernández por su ayuda en la recolecta del material; a los M.C. Andrés Orduño Cruz y Sofía Loza Cornejo por sus valiosas sugerencias para mejorar el manuscrito; al Sr. Miguel Vega por el trabajo fotográfico de cuarto obscuro y al Dr. Sergio Cevallos-Ferriz y un revisor anónimo sus comentarios favorables al manuscrito

\section{Literatura citada}

Abbe L.B. y Crafts A.S. 1939. Phloem of white pine and other coniferous species. Botanical Gazette 100:695-722.

Chang Y. 1954. Bark structure of North American conifers. USDA. FPL. FS. Technical Bulletin 1095:1-86.

Eremin V.M. 1978. Bark anatomy of the species of Pinus of the Soviet Union. Botanicheskii Zhurnal 63:649-663. 
Esau K. 1953. Plant anatomy. Wiley, USA.

Grillos S.J. y Smith F.H. 1959. The secondary phloem of the Douglas fir. Forest Science 5: 377-388.

Gutiérrez-Hernández J.F. 1997. Inventario dasonómico urbano de los árboles del campus de la Universidad Autónoma Chapingo. Tesis profesional. División de Ciencias Forestales. UACh. Chapingo, México, $105 \mathrm{pp}$.

Harlow W.M. Harrar E.S. Hardin J.W. y White F.M. 1991. Textbook of Dendrology. 7th. ed. McGraw-Hill. USA.

Hillis W.E. 1987. Heartwood and tree exudates. Springer-Verlag. New York.

Iqbal M. y Zahur M.S. 1995. Secondary phloem. En: Iqbal M. (Edr.) The cambial derivatives. Gebrüder Borntraeger, Berlin, 210-240.

Isenberg I.H. 1943. The anatomy of redwood bark. Madroño 7:85-91.

Johansen D.A. 1940. Plant microtechnique. McGraw-Hill. USA.

Jones S.B. 1988. Sistemática vegetal. 2a. ed. McGraw-Hill. México.

Junikka L. 1994. Survey of English macroscopic bark terminology. IAWA Journal 15:3-45.

Krüssmann G. 1985. Manual of cultivated conifers. Timber Press. Oregon.

Liphschitz N. Lev-Yadun S. y Waisel Y. 1981. The annual rhytm of activity of the lateral meristems (cambium and phellogen) in Cupressus sempervirens L. Annals of Botany 47:485-496.

Martínez M. 1948. Los pinos mexicanos. 2a. ed. BOTAS. México, D.F.

Martínez M. 1953. Las pináceas mexicanas. SARH. SRFC. México, D.F.

Miller C.N. 1988. The origin of modern conifer families. En: Beck C.B. (Edr.). Origin and evolution of gymnosperms. Columbia University Press, Chicago, 448-486.
Nunes E. Quilhó T. y Pereira H. 1996. Anatomy and chemical composition of Pinus pinaser bark. IAWA Journal 17:141-149.

Outer R.W. den. 1967. Histological investigations of the secondary phloem of gymnosperms. Mendelingen Landbouwhogeschool Wageningen 67:1-119.

Panshin A.J. y de Zeeuw C. 1980. Textbook of wood technology. 4th. Ed. McGraw-Hill Book, New York.

Perry J.P. 1990. The pines of Mexico and Central America. Timber Press. Oregon.

Prance G.T. y Prance A.E. 1993. Bark: the formation, characteristics and uses of bark around the world. Timber Press. Oregon.

Rothwell G.W. y Serbet R. 1994. Lygnophyte phylogeny and the evolution of spermatophytes: a numerical cladistic analysis. Systematic Botany 19:443-482.

Srivastava L.M. 1963. Secondary phloem in the Pinaceae. University of California Publications in Botany 36:1-42.

Srivastava L.M. 1964. Anatomy, chemistry, and physiology of bark. International Review Forest Research 1:203-277.

Smoot E.L. 1984a. Secondary phloem anatomy in Callystophyton boyssetii (Renault) Rothwell and histological changes in the outer phloem. Botanical Gazette. 145:395-406.

Smoot E.L. 1984b. Phloem anatomy of the Carboniferous pteridosperm medullosa and evolutionary trends in gymnosperm phloem. Botanical Gazette. 145:550-564.

Taylor E.L. 1991. Phloem evolution: an appraisal based on the fossil record. En: Behnke H.D. y Sjolund R.D. (Edrs.). Sieve elements, comparative structure, induction and development. Springer-Verlag, Germany, 285-298.

Zamudio S. 1992. Familia Taxaceae. Flora del Bajío y de regiones adyacentes. Instituto de Ecología, A.C. Fascículo 9:1-7. 
Apéndice 1: Clave para la identificación

1. Corteza fisurada

$1^{\prime}$. Corteza no fisurada

2. Células de parénquima axial dispersas. En el ritidoma se observa parénquima dilatado fuertemente

$2^{\prime}$. Células de parénquima axial en bandas tangenciales

3. Células de parénquima axial con estiloides

$3^{\prime}$. Células de parénquima axial sin cristales

4. Radios homogéneos

4'. Radios heterogéneos

5. Con canales resiníferos radiales y longitudinales

5'. Unicamente con canales resiníferos radiales

6. Corteza lisa con escamas exfoliantes. Las células cribosas arregladas en bandas tangenciales

6'. Corteza no lisa

7. Corteza rugosa ligeramente reticulada. Las células cribosas distribuidas en las bandas tangenciales de parénquima

$7^{\prime}$. Corteza no rugosa

8. Corteza laminar. Arreglo celular en bandas tangenciales estratificadas

8'. Corteza no laminar

9. Corteza escamosa

9'. Corteza fibrosa

10. Una peridermis, sin esclereidas

$10^{\prime}$. Peridermis sucesivas

11. Con cristales romboédricos sobre las paredes de las células cribosas, de parénquima y fibras

$11^{\prime}$. Con abundantes cristales romboédricos sobre las paredes de las fibras y escasos en las de parénquima

12. Células del parénquima axial expandidas en las bandas tangenciales del floema secundario

12'. Células del parénquima axial no expandidas en el floema secundario

13. Sin canales resiníferos y con ritidoma

$13^{\prime}$. Con canales resiníferos longitudinales y sin ritidoma

14. Células cribosas se distribuyen en las bandas tangenciales de parénquima axial

14'. Células cribosas arregladas en bandas tangenciales

15. Sin ritidoma

15'. Con ritidoma

16. Los radios no se dilatan en el floema colapsado

16'. Los radios se dilatan en el floema colapsado
2

6

3

4

Pinus patula

Pinus oaxacana

Cedrus libani

5

Pinus maximartinezii

Pinus cembroides

Cupressus guadalupensis 7

Ginkgo biloba

8

Cryptomeria japonica

9

10

12

Taxus globosa

11

Araucaria excelsa

Araucaria bidwillii

13

14

Chamaecyparis lawsoniana

Calocedrus decurrens

Taxodium mucronatum 15

Juniperus monosperma

16

Cupressus lusitanica

Cupressus arizonica 